\title{
Knowledge sourcing in a traditional industry: prospects of peripheral regions
}

\section{János Gyurkovics* and Zsófia Vas}

Faculty of Economics and Business Administration, University of Szeged,

Kálvária Ave. 1, 6722, Szeged, Hungary

Email: gyujan@eco.u-szeged.hu

Email: vas.zsofia@eco.u-szeged.hu

*Corresponding author

\begin{abstract}
Despite its economic relevance, only a few studies focus on knowledge creation, diffusion and utilisation in traditional industries located in peripheral regions, and even fewer on the innovation interdependencies between industries and regions. The theory of differentiated knowledge bases is capable to explain both the industrial and spatial patterns of the knowledge flows. The present study aims to reveal the process of innovation-related knowledge sourcing in the printing industry located in the peripheral region of Kecskemét, Hungary. The research builds on three main questions: what are the main sources of new knowledge? Who are the main collaborative partners in knowledge acquisition and transfer? And what is the main spatial level of knowledge sourcing? The results indicate that in a peripheral region, innovative firms build on the combination of direct and indirect knowledge sources mostly external to the region, while the non-innovative ones typically rely on local, incomplex knowledge sources.
\end{abstract}

Keywords: innovation; differentiated knowledge bases; traditional industry; peripheral region; Hungary; knowledge sourcing.

Reference to this paper should be made as follows: Gyurkovics, J. and Vas, Zs. (2018) 'Knowledge sourcing in a traditional industry: prospects of peripheral regions', Int. J. Innovation and Learning, Vol. 24, No. 2, pp.220-237.

Biographical notes: János Gyurkovics is a Lecturer of Faculty of Economics and Business Administration at the University of Szeged. His academic and research experience is related to knowledge flows, knowledge networks, innovation and innovation systems.

Zsófia Vas is an Assistant Professor of Faculty of Economics and Business Administration at the University of Szeged. Her research activity is focused on regional economic development, regional clusters, innovation systems and industrial knowledge bases.

This paper is a revised and expanded version of a paper entitled 'Knowledge dynamics in a traditional industry of Hungary' presented at Regional Innovation Policies Conference, Cardiff, 3-4 November 2016. 


\section{Introduction}

How is the creation, diffusion and utilisation of economically useful knowledge carried out at firm-level? How can a firm respond to challenges by the means of learning? What factors explain the differences in the innovation and economic performance of firms and their regional base? Providing answers to such questions has been the focus of research for several decades.

Many theoretical approaches are engaged in grasping the characteristics of knowledge sourcing processes between firms. One of the most prominent among these is the theory of differentiated knowledge bases (Asheim and Gertler, 2005; Asheim et al., 2007, 2011), which explains both the industrial and spatial characteristics of knowledge sourcing. The theory highlights the specificities of industrial knowledge creation, diffusion and utilisation on the basis of the combination of industrial knowledge elements and competences, i.e., the industrial knowledge base (Dosi, 1988), and also takes account of the spatial patterns of knowledge processes.

Our dilemma, which defines the objective of the research is the little information about the impact of peripheral regional business environment on firms' activity (Gülcan et al., 2011; Lengyel, 2012), even though these regions face special barriers of innovation (Tödtling and Trippl, 2005). Most of the times researches connected to knowledge sourcing focus on advanced regions because it is assumed that the economic performance of such regions is related to the local concentration of knowledge intensive economic activities which are nourished by the constant flow of knowledge. In contrast in peripheral regions knowledge sourcing is barely examined since it is assumed to be hindered by, among others, the lack of social capital and trust (Tödtling and Trippl, 2005).

Based on advanced economies, there is a variety of empirical evidence using the industrial knowledge bases framework, however it is less described how non-core areas without cluster initiatives, highly specialised workforce and services (Tödtling et al., 2011), sectors playing a leading role in technology development far from sources of knowledge creation and dissemination (Lagendijk and Lorentzen, 2007) may rise out from the peripheral status.

Many studies - including the ones in peripheral regions of Hungary (Csizmadia and Grosz, 2011; Szakálné and Vas, 2013) - highlight the distinctive nature of economic activities, i.e., that traditional industries differ from the knowledge-intensive economic activities in several aspects (Tödtling et al., 2006; Vega-Jurado et al., 2009; Trippl, 2011; Krafft et al., 2014). However, regarding the analysis of knowledge sourcing and learning processes, the majority of research focuses on knowledge-intensive industries. The innovation and knowledge sourcing in traditional industries, which are dominated mainly by smaller actors with structurally fragmented connections, characterised by limited internal R\&D activities and a lower proportion of a highly-qualified workforce (Spithoven et al., 2011), are less addressed research topics. However, their economic significance, e.g., their role in employment, is not negligible, and they could be important sources of growth in peripheral regions through their innovation activity. 
Based on the above described research gaps, the aim of the paper is to present the innovation-related knowledge sourcing, i.e., the characteristics of knowledge acquisition and transfer, of firms in a traditional industry by applying the concept of differentiated knowledge bases. The research was carried out among the firms of the printing industry in Kecskemét, Hungary, because of the peripheral nature of the region, the high spatial concentration of firms and the remarkable history of the industry. We examined innovation-related knowledge sourcing along three main questions: what are the main sources of new knowledge? Who are the main collaborative partners in knowledge acquisition and transfer? And what is the main spatial level of knowledge sourcing? The relevance of our research is the application of the theory of differentiated knowledge bases in a traditional industry located in a peripheral region.

The paper is structured as follows: first, we describe the role of knowledge and learning on the firm-level. Then we outline the methodology of our research, we briefly describe the printing industry in Kecskemét and elaborate on the results of the questionnaire survey. Finally, we systematise our major conclusions and we discuss the relevant policy issues.

\section{The knowledge-based theory of firms and industries}

Firms are the medium of knowledge integration (Grant, 1996). Opinions vary as to whether organisational knowledge actually exists (Simon, 1991; Levitt and March, 1988), but basically the organisational knowledge base is the combination of various knowledge elements and competences (Dosi, 1988). It can be developed in-house (e.g., by internal $R \& D$ ), or by external sources. What is important that those who examine innovation on network bases and use innovation system approach reveal that the success of developing marketable knowledge depends mainly on the external relations of the firms (Cooke and Morgan, 1993). Due to the fact that an organisation is unlikely to possess all the necessary resources; it interacts with other actors and gets involved in a learning process (Lundvall, 1992).

The creation, diffusion and utilisation of economically useful knowledge is explained by many theoretical approaches, a part of which take account of the effects resulting from the diversity of industries, for example the absorptive capacity (Cohen and Levinthal, 1990), the concept of open innovation (Chesbrough, 2003), or the STI and DUI innovation modes (Jensen et al., 2007). The other part of literature studies the role of spatiality, such as the theory of innovation systems (Lundvall, 1992), innovative milieu (Camagni, 1995), learning regions (Florida, 1995), local buzz and global pipelines (Bathelt et al., 2004), geographical and relational proximity (Boschma, 2005), or localised learning and networks (Malmberg and Maskell, 2006).

The theory of differentiated knowledge bases provides an explanation for the joint effect of the different kinds of knowledge, the type of economic activities and spatiality (Asheim and Gertler, 2005; Asheim et al., 2007, 2011). The essence of the theory is that the firm-level and industrial knowledge base has an effect on the knowledge-based and learning processes, as well as on the type and spatiality of innovative activities. The theory defines three prominently different knowledge bases. The main objective of the activities relying on an analytical, science-based knowledge base (e.g., pharmaceuticals) is to create a radically new product or process, which is generally the result of formalised 
university-industry collaboration, as well as basic and applied research. The creation of highly codifiable new knowledge is often based on former scientific publications and patents. Geographical distance is a minor obstacle in the diffusion of knowledge. The firms are often involved in global networks and located in the proximity of highly-qualified workforce and knowledge producing institutions.

The economic actors building on a synthetic, engineering-based knowledge base (e.g., machinery) generally try to introduce innovation by a novel application and combination of existing knowledge. The creation of mainly tacit, know-how type knowledge is problem-oriented, context-specific and based primarily on practical skills and customer and supplier interactions. R\&D activities are less common. Synthetic knowledge-based firms generally employ staff with technical qualifications: they either train their employees or occasionally poach them from their competitors. The economic actors have some global partnerships, local embeddedness is moderate.

Finally, in the case of symbolic, arts-based activities (e.g., film production), innovation is generated by combining existing knowledge in a novel way to create new, creative products and aesthetic values. R\&D activities are uncommon. The knowledge base consists mostly of context-specific, tacit knowledge. Knowledge transfer is often carried out in the framework of short, project-based collaborations in local networks through learning-by-doing. Local embeddedness and a strong influence of economic and social background are significant.

Empirical findings reveal that firms which rely on the combination of at least two knowledge bases have higher innovation activity (Tödtling and Grillitsch, 2015; Zukauskaite and Moodysson, 2013). Usually industries can be defined by one dominant knowledge base, which has a crucial effect on the innovation networks and the spatiality of the industry (Martin and Moodysson, 2011, 2013; Liu et al., 2013). However, the dominant knowledge base may change over the time (Plum and Hassink, 2011). Furthermore, the knowledge acquired from more than one spatial level leads to higher innovation performance (Tödtling and Grillitsch, 2015). At the same time, it becomes clear that the industrial knowledge base itself fails to explain the differences in innovation and economic performance. The difference between the same kinds of industries in two distinct regions is greater than between two different industries in the same region (Chaminade, 2011). Consequently, different regional innovation systems result in different innovation performance (Gülcan et al., 2011).

In peripheral regions, less developed, non-core areas with low level of investments, prevalence of SMEs, lack of advanced infrastructure, services and strong traded sectors and cluster initiatives (Lagendijk and Lorentzen, 2007; Tödtling et al., 2011), innovation has barriers, such as low level of innovation and R\&D activities and expenditures, the lack of highly-qualified workforce and specialised services, or organisational thinness (Tödtling and Trippl, 2005). For this reason, in peripheral regions, external knowledge sources are of higher importance (Rosenfeld, 2002). Based on some former empirical analyses which build on the theory of differentiated knowledge bases and focus on less developed regions, it can be established that direct collaborations with knowledge-creating organisations are uncommon, the institutional background is weak, there is a risk of technological lock-in and the spatiality of interactions is very different, which is obviously highly influenced by the type of the economic activity (Gülcan et al., 2011; Chaminade, 2011). 
The difference between traditional and knowledge-intensive economic activities in spatial distribution, innovation and industrial knowledge base is also proven (Tödtling et al., 2006; Vega-Jurado et al., 2009; Trippl, 2011; Krafft et al., 2014; Csizmadia and Grosz, 2011; Szakálné and Vas, 2013). The firms of traditional, low-technology industries are much more interested in acquiring external knowledge than sharing their knowledge with other actors (Chesbrough and Crowther, 2006). Although their absorptive capacity is lower because of this, their networks can be local, national and international in scope (Kaufmann and Tödtling, 2000). Their most important partners are customers and suppliers, and their collaborations requiring frequent interaction are typically local, due to the necessity of face-to-face communication.

\section{Research methodology}

In our empirical research, we study the characteristics of knowledge sourcing, i.e., knowledge acquisition and transfer related to innovation in a traditional industry concentrated in a peripheral region, in relation to three main questions: What are the main sources of new knowledge? Who are the main collaborative partners in knowledge acquisition and transfer? And what is the main spatial level of knowledge sourcing? Our aim is to provide a picture of the knowledge sourcing pattern of firms in a traditional industry of a peripheral region in a descriptive way. We consider traditional industries as ones dominated mainly by smaller actors with structurally fragmented connections, characterised by limited internal R\&D activities and a lower proportion of highly-qualified workforce (Spithoven et al., 2011).

Many previously presented studies have examined the patterns of knowledge sourcing processes between firms within the same industry based on the theory of differentiated knowledge bases, of which we use Martin and Moodysson's $(2011,2013)$ methodology as a basis. According to the authors, firms can acquire new knowledge in three distinct ways.

- Monitoring: An indirect way of knowledge sourcing, when the actors do not have direct contact with the sources of knowledge (e.g., universities, competitors), but they acquire new knowledge through an intermediary (e.g., scientific journals, fairs).

- Mobility: A direct way of knowledge sourcing, through the recruitment of skilled workforce from other actors (e.g., universities, firms of the industry).

- Collaboration: A direct way of knowledge sourcing, through collaborations between organisations, in which process the firms acquire new knowledge by directly interacting with other actors.

Our research was conducted in January 2016 using questionnaire based on Martin and Moodysson's $(2011,2013)$ earlier research in terms of both the type of survey and the evaluation method of the obtained results in order to allow for further comparison. In the questionnaire, after initial demographic questions, respondents evaluated the importance they attach to the knowledge sources (e.g., higher education institutions, competitors) of a particular dimension (monitoring, mobility, collaboration) in their knowledge acquisition activities on a Likert scale ranging from 1 (not at all) to 4 (high). In most cases, the executive officers were asked, but when it was not possible, another person in a senior position who had the required information was responded. Since some changes were 
made in the questionnaire compared to the original Martin and Moodysson $(2011,2013)$ research, a few pilot surveys were conducted to test the clarity, reliability and validity of our questionnaire. The final survey was administered in person. For anonymity, respondents were identified by numbers, and there was no question about the name of the company.

Besides the relative importance of the sources, we also examine the most common spatial levels of knowledge sourcing. Thus we differentiate the actors within the categories of mobility and collaboration according to whether they operate at local, national or international levels. The local level covers Kecskemét and its surrounding area, the national level includes every other Hungarian region, while the international refers to areas outside the country.

We also assume that firms which perform innovation activities have a slightly different knowledge acquisition and transfer pattern, and thus we categorise firms as innovative and non-innovative based on the responses. Following international practice, 'innovative' refers to firms which claim to have introduced new product or process, improved their own product or process, or carried out an innovation in their marketing and/or organisational processes in the past three years. Compared to Martin and Moodysson's $(2011,2013)$ research, this categorisation can give a more accurate picture of what knowledge sources are actually important for firms engaged in innovation activities in a traditional industry and at what spatial level. Overall, the analysis of monitoring provides a picture of the most important sources of knowledge while the most important partners and the spatiality of knowledge sourcing are shown by unfolding the characteristics of mobility and collaboration.

The subject of our research is the printing industrial firms concentrated in the region of Kecskemét, Hungary. The rural city region of Kecskemét with its population of 110,000 is located in one of the least competitive NUTS2 regions of the EU, the Southern Great Plain region (Lengyel and Rechnitzer, 2013). In its NUTS2 region, the rate of employment and the GDP per capita is below the national average, and the impact of central planning and the role of public R\&D is substantial in the region (Lengyel and Leydesdorff, 2011). Despite the fact that Kecskemét is among the 10 biggest cities in Hungary its economic development is lag behind compared to similar EU cities. Kecskemét does not have major industrial traditions. Leading economic activities thanks to the geographical features - are related mainly to the food industry. Other activities, such as engineering or printing have appeared after World War II. Although the automotive industry has been expanded in the previous years, only low value added, assembly activities are present in Kecskemét. Knowledge intensive sectors are missing from the city region but it seems that traditional industrial firms, such printing, have a considerable concentration in the area.

The history of the industry dates back to the 1840s, when the first printing house, later called STI Petőfi Printing House, was established in the city, whose successor is still operating (Juhász and Lengyel, 2016). From the 1990s, several domestic private printing industrial firms have been set up, many of them as a spin-off of the Petöfi Printing House, and some foreign owned enterprises have been established as well. The printing industry of Kecskemét is dominated by small- and medium-sized enterprises, which are specialised primarily in the manufacture of unique products in small series (e.g., specifically printed and folded, unique paper products, packaging materials, labels). A secondary vocational school for printing technology is also found in the region, providing 
a potential supply of skilled workforce. Research and development activities are not common in the printing industry of Kecskemét, and the proportion of highly-qualified people is low, which collectively indicate the traditional character of the industry. Furthermore, according to Juhász and Lengyel's (2016) results based on location quotient (LQ), printing activities ( $\mathrm{LQ}=1.048)$, as well the manufacture of paper products $(\mathrm{LQ}=3.777)$ is relatively strongly concentrated in Kecskemét based on the number of employees.

Overall, the peripheral nature of Kecskemét alongside the relatively high geographical concentration and remarkable history of the industry, furthermore the similar social and historical background of firms make the printing industry of Kecskemét a suitable case for studying the processes of knowledge sourcing.

In line with Juhász and Lengyel (2016) printing industrial firms refer to companies which conduct their main activities in the 17 (manufacture of paper and paper products) or 18 (printing and reproduction of recorded media) sectors according to NACE Rev. 2. These firms are altogether referred to as the printing industry. First, we excluded firms which have their headquarters outside the Kecskemét city region then firms with less than 2 employees in the last financial year, which left 37 companies in our targeted population. The final dataset consists of 26 firms which is $70 \%$ of the population. Eleven companies were either refused to respond or not operated at their official headquarters.

Our assumptions regarding the characteristics of knowledge sourcing in traditional industries are formulated in the next chapter, at the beginning of each section presenting the results related to each dimension. The analysis is conducted in a descriptive way, providing a picture of the most common modes of knowledge sourcing processes in a traditional industry. The results are presented by dimensions, as the rate of responses related to a particular knowledge source, separated according to importance.

\section{The characteristics of knowledge sourcing in the printing industry}

The analysed sample consists of 26 printing industrial firms in the region of Kecskemét. In terms of their main activities, the majority (42.3\%) conduct printing activities, while equally one quarter $(23.1 \%)$ of the firms are engaged in pre-press services and one quarter in the manufacture of paper products respectively. One tenth (11.5\%) of the firms indicated other fields of activity as main activities (e.g., binding or manufacture of printing equipment). The average age of the firms (18.1 years) shows that it is a relatively mature industry. The industry is dominated by microenterprises with less than 10 employees $(69.2 \%)$ and only one quarter $(23.1 \%)$ of the firms can be classified as small- or medium-sized enterprises. The only large company is the STI Petöfi Printing House. In terms of innovation activity, the firms are evenly divided: 14 companies can be considered innovative (53.8\%), while 12 performed no innovation activities (46.2\%) over 3 years prior to the survey.

The main sources of knowledge, the spatiality of knowledge sourcing and the nature of collaborations all depend primarily on the dominant industrial knowledge base. However, the categorisation of industries according to knowledge bases is often based only on theoretical assumptions, and as the literature indicates, there is no industry which 
could be characterised by a single knowledge base, although a dominant knowledge base can usually be determined. In our research, we assume that the printing industry has specificities which can essentially be attributed to the existence of a synthetic knowledge base, which can be pointed out by the primary analysis of the employees' actual activities. On the basis of the literature, firms with a synthetic knowledge base employ a workforce performing mostly engineering activities. The work is practice- and problem-oriented; the source of innovation is a novel application and combination of existing knowledge.

Supporting our assumptions, the composition of the workforce in the firms reveals that the printing industry of Kecskemét is clearly dominated by activities defined by a synthetic knowledge base. More than half $(52.7 \%)$ of the full-time employees are printers (printer/machine minder, operator, block maker), the proportion of which is not changed even with the exclusion of STI. The percentage of pre-press occupations (designers and graphic artists) relying on a symbolic knowledge base is also considerable, but they constitute only $14.2 \%$ of the employees, excluding STI. One possible explanation for the relatively higher proportion of activities relying on a symbolic knowledge base is that in the local industry smaller firms focus on unique, small-scale production, where creative solutions and the creation of unique designs are important.

We study the main sources of knowledge acquisition activities of the printing industrial firms in Kecskemét, in line with Martin and Moodysson's (2011, 2013) methodology, by distinguishing four knowledge sources within the dimension of monitoring: fairs and exhibitions which focus on the latest industrial news, trends and technologies; professional magazines, including online journals specialised in industrial news; surveys conducted by professional support organisations (e.g., chambers, statistical offices) or businesses; and scientific journals. Based on the theory, we expect that the secondary sources are not of major importance for the firms in the industry because they focus primarily on direct interaction, on the collaborations with customers and suppliers in the process of knowledge acquisition.

Contrary to our expectations, the results show that firms of the printing industry in Kecskemét tend to rely on secondary sources in their knowledge acquisition activities. Only one tenth $(11.5 \%)$ of the firms do not use any kind of indirect sources, while one third of them simultaneously rely on two sources. There is a substantial difference between innovative and non-innovative firms. The latter use only two or fewer sources. One third (35.7\%) of the innovative firms use three, while $21.4 \%$ simultaneously use all four given sources to acquire new knowledge.

The number of sources is closely linked to the differences observed in their relative importance. The innovative and non-innovative firms both consider professional magazines as their most important indirect knowledge source (Table 1). More than 70\% of the innovative firms and half of the non-innovative companies assessed professional magazines as at least moderately important. The second most important sources are fairs and exhibitions, which have closely similar significance for the two groups. The greatest discrepancy between the innovative and non-innovative firms is found in the use of surveys and scientific journals. While one third (35.7\%) of the innovative firms consider these two sources at least moderately important in acquiring new knowledge, the non-innovative firms do not regard them important at all $(91.7 \%)$. 
Table 1 Monitoring: relative importance of the indirect sources of knowledge acquisition among innovative and non-innovative firms (\%)

\begin{tabular}{llcccc}
\hline & & $\begin{array}{c}\text { Fairs, } \\
\text { exhibitions }\end{array}$ & Magazines & Surveys & $\begin{array}{c}\text { Scientific } \\
\text { journals }\end{array}$ \\
\hline \multirow{2}{*}{ High } & I & 14.3 & 42.9 & 21.4 & 35.7 \\
& NI & 8.3 & 33.3 & 0.0 & 0.0 \\
\multirow{5}{*}{ Loderate } & I & 28.6 & 28.6 & 14.3 & 0.0 \\
& NI & 33.3 & 16.7 & 0.0 & 0.0 \\
\multirow{3}{*}{ Not at all } & I & 50.0 & 7.1 & 7.1 & 7.1 \\
& NI & 16.7 & 25.0 & 0.0 & 0.0 \\
& I & 7.1 & 14.3 & 57.1 & 57.1 \\
& NI & 33.3 & 16.7 & 91.7 & 91.7 \\
\hline
\end{tabular}

Notes: The proportion of non-respondents is not indicated.

I - innovative, NI - non-innovative.

Source: Own construction

We can overall conclude that the most basic market and technological knowledge can be accessed by the industry in fairs and exhibitions. Nevertheless, this is complemented by firms conducting innovation activities with knowledge from surveys and scientific works. In the case of an industry relying dominantly on a synthetic knowledge base, we may expect a different pattern as the former sources have a greater importance primarily in the industries characterised by a symbolic knowledge base, where innovations are unique and knowledge acquisition takes place through personal interactions. At the same time, considering the local characteristics of the printing industry in Kecskemét (SMEs specialised in the manufacture of unique products), the results are less surprising.

The main partners involved in the knowledge acquisition activities of the printing industrial firms in Kecskemét are first examined through the mobility of the workforce, the recruitment of highly-qualified people. In the industries dominated by a synthetic knowledge base and characterised by experimenting, testing and learning-by-doing, the role of workforce with practical industrial experience is crucial. Thus the companies of the printing industrial firms in Kecskemét are presumably less likely to seek for entrants freshly graduated from higher education or vocational training schools.

Our results indicate that in the case of knowledge acquisition through the recruitment of skilled workforce among the printing industrial firms in Kecskemét, the examined actors are of low importance (Table 2). Irrespective of innovation activity, about $35 \%-40 \%$ of the firms do not consider any of the actors as an important source in the recruitment of skilled workforce. The low relative importance of training institutions is even more surprising, given that a vocational school specialised in printing industrial training is located in the city.

Alongside typical partners, we also examined the spatiality of knowledge sourcing through mobility. In the case of firms which rely on at least one knowledge source, the highest relative importance is attached to the recruitment from local actors within the industry. One third of the innovative firms (35.7\%) and one quarter of the non-innovative companies consider local actors at least moderately important. In addition, innovative firms rely on attracting workforce from other printing companies to a greater degree at the national level as well $(28.5 \%)$. Workforce recruitment from related industries has importance at both the local and national levels only in the case of innovative firms. 
Table 2 Mobility: relative importance of the sources of skilled workforce among innovative and non-innovative firms (\%)

\begin{tabular}{|c|c|c|c|c|c|c|c|}
\hline & & \multicolumn{3}{|c|}{ Higher education institution } & \multicolumn{3}{|c|}{ Vocational training school } \\
\hline & & $L O C$ & $N A T$ & $I N T$ & $L O C$ & $N A T$ & INT \\
\hline \multirow[t]{2}{*}{ High } & I & 7.1 & 14.3 & 0.0 & 14.3 & 7.1 & 0.0 \\
\hline & NI & 0.0 & 0.0 & 0.0 & 16.7 & 0.0 & 0.0 \\
\hline \multirow[t]{2}{*}{ Moderate } & I & 0.0 & 0.0 & 7.1 & 0.0 & 7.1 & 7.1 \\
\hline & NI & 0.0 & 0.0 & 8.3 & 0.0 & 0.0 & 0.0 \\
\hline \multirow[t]{2}{*}{ Low } & I & 7.1 & 14.3 & 0.0 & 21.4 & 14.3 & 7.1 \\
\hline & NI & 0.0 & 0.0 & 0.0 & 0.0 & 0.0 & 0.0 \\
\hline \multirow[t]{4}{*}{ Not at all } & I & 78.6 & 64.3 & 85.7 & 64.3 & 71.4 & 85.7 \\
\hline & NI & 91.7 & 91.7 & 83.3 & 75.0 & 91.7 & 91.7 \\
\hline & & \multicolumn{3}{|c|}{ Same industry } & \multicolumn{3}{|c|}{ Related industry } \\
\hline & & $L O C$ & $N A T$ & $I N T$ & $L O C$ & $N A T$ & $I N T$ \\
\hline \multirow[t]{2}{*}{ High } & I & 21.4 & 7.1 & 0.0 & 7.1 & 7.1 & 0.0 \\
\hline & NI & 0.0 & 0.0 & 0.0 & 0.0 & 0.0 & 0.0 \\
\hline \multirow[t]{2}{*}{ Moderate } & I & 14.3 & 21.4 & 7.1 & 21.4 & 21.4 & 7.1 \\
\hline & NI & 25.0 & 0.0 & 0.0 & 0.0 & 0.0 & 0.0 \\
\hline \multirow[t]{2}{*}{ Low } & I & 7.1 & 14.3 & 7.1 & 7.1 & 14.3 & 21.4 \\
\hline & NI & 0.0 & 0.0 & 0.0 & 25.0 & 0.0 & 0.0 \\
\hline \multirow[t]{2}{*}{ Not at all } & I & 57.1 & 57.1 & 85.7 & 64.3 & 57.1 & 71.4 \\
\hline & NI & 66.7 & 91.7 & 91.7 & 66.7 & 91.7 & 91.7 \\
\hline
\end{tabular}

Notes: The proportion of non-respondents is not indicated.

LOC - local, NAT - national, INT - international, I - innovative,

$\mathrm{NI}$ - non-innovative.

Source: Own construction

Our results therefore verify our assumptions, as in the printing industry of Kecskemét characterised dominantly by a synthetic knowledge base: the importance of higher educational institutions and vocational training schools is relatively low. The studied industry, in the case of innovative firms in particular, is characterised by workforce mobility between local printing industrial firms, and innovative firms tend to recruit from related industries at the local and national level.

We also examined the collaboration partners and the spatiality of knowledge sourcing based on direct interactions between firms, generally targeted at product development, exploitation of new market opportunities or joint procurement of technologies. Due to the partially tacit nature of a synthetic knowledge base, knowledge gained from personal interactions is expected to have a more significant role in the industry. For its examination, the firms indicated the degree they rely on various actors in acquiring and transferring new knowledge. In line with the theory, we expect customers and suppliers to be of relatively higher importance, while we assess the cooperation with competitors as less important due to intensive competition. We also consider the importance of higher educational institutions only secondary, apart from the fact that the significance of 
applied research in the industries building on a synthetic knowledge base is not negligible.

Based on the rate of responses of moderate and high importance, the most important direct knowledge sources are customers and suppliers. However, while customers are crucial sources of new knowledge irrespective of innovation activities, suppliers are of great significance mainly for innovative companies. In their case, international suppliers are in the first position; half of the firms consider them as at least a moderately important external knowledge source. Non-innovative firms are not likely to collaborate with local suppliers, only one quarter of them regards national suppliers as at least a moderately important external knowledge source, while less than one fifth of them (16.6\%) think the same of international suppliers.

In terms of customers, the difference is smaller between the two groups. $43 \%$ of the innovative firms assess local customers as at least moderately important in their learning processes, but collaborations with national (35.7\%) and international (35.7\%) customers are also significant. For non-innovative firms, local and national customers can be considered similarly important (41.7\%), while the significance of international customers is negligible. Interestingly, in the case of non-innovative firms, local competitors are the second most important external knowledge sources, while collaboration with them is less prominent for innovative firms. Higher educational institutions, as one of the greatest sources of new knowledge, have certain significance only in the case of innovative firms, although their importance is still behind the other knowledge sources.

We also studied the combination of external knowledge sources (Table 3). There is one innovative and one non-innovative firm which do not collaborate with any of the above-mentioned actors in the process of knowledge acquisition and transfer. The proportion of companies relying on one source is only $7.7 \%$ in the total sample, while the rest of the printing industrial firms of Kecskemét simultaneously collaborate with several external actors if they need new knowledge.

Table 3 Collaboration: combination of direct sources of knowledge acquisition among innovative and non-innovative firms (\%)

\begin{tabular}{lcc}
\hline & $\begin{array}{c}\text { Innovative } \\
\text { firms }\end{array}$ & $\begin{array}{c}\text { Non-innovative } \\
\text { firms }\end{array}$ \\
\hline None & 7.1 & 8.3 \\
Suppliers & 7.1 & 0.0 \\
Competitors & 0.0 & 8.3 \\
Customers and suppliers & 14.3 & 16.7 \\
Customers and competitors & 0.0 & 16.7 \\
Suppliers and competitors & 0.0 & 8.3 \\
Customers, suppliers and competitors & 28.6 & 33.3 \\
Customers, suppliers and higher education institutions & 7.1 & 0.0 \\
Customers, competitors and higher education institutions & 0.0 & 8.3 \\
Customers, suppliers, competitors and higher education & 35.8 & 0.0 \\
institutions & & \\
\hline
\end{tabular}

Note: The proportion of non-respondents is not indicated.

Source: Own construction 
The most common feature among innovative firms is that they rely on all four groups at the same time in the process of knowledge acquisition $(35.8 \%)$. This is followed by the firms which build on knowledge obtained from their customers, suppliers and competitors $(28.6 \%)$, while only $14.3 \%$ use only the knowledge provided by customers and suppliers. The results show that higher educational institutions were mentioned only together with the three other sources. This demonstrates that the theoretical knowledge they provide is applied by innovative firms only in combination with practice-oriented knowledge, obtainable mainly from other actors. Non-innovative firms do not rely on knowledge gathered from higher educational institutions; however, they most commonly acquire knowledge from more than one actor at the same time. One third of the respondents (33.3\%) build on knowledge gained simultaneously from customers, suppliers and competitors, while $16.7 \%$ combines knowledge acquired from customers with knowledge gathered from suppliers or competitors. Consequently, firms of the printing industry in Kecskemét rely primarily on knowledge acquired from customers and suppliers, which they complement with knowledge gathered from competitors and, in the case of innovative firms, from higher educational institutions.

Focusing on the spatiality of actors, we expected local contacts to have higher importance, which are necessary because of personal interactions and the transfer of tacit knowledge, but that extra-regional contacts would also be common. Nevertheless, the results provide a slightly different picture than our expectations (Table 4). Interestingly, the local level itself is not of high importance in either group. $7.1 \%$ of innovative firms and $16.7 \%$ of non-innovative companies rely solely on locally accessible knowledge. Neither group relies on knowledge acquired only from international actors, which is not surprising due to a higher demand of the industries with a synthetic knowledge base for tacit knowledge. $41.7 \%$ of non-innovative firms primarily acquire new knowledge collectively from the local and national levels, while one quarter of the companies also rely on sources external to the country. In contrast, more than half of the innovative firms $(57.1 \%)$ gather the required knowledge from all three spatial levels at the same time.

Table 4 Collaboration: spatiality of direct sources of knowledge acquisition among innovative and non-innovative firms (\%)

\begin{tabular}{lcc}
\hline Spatial level & Innovative firms & Non-innovative firms \\
\hline None & 7.1 & 8.3 \\
Local & 7.1 & 16.7 \\
National & 14.3 & 0.0 \\
International & 0.0 & 0.0 \\
Local and national & 7.1 & 41.7 \\
Local and international & 0.0 & 0.0 \\
National and international & 7.1 & 8.3 \\
Local, national and international & 57.1 & 25.0 \\
\hline
\end{tabular}

Source: Own construction

Overall, the printing industrial firms in Kecskemét rely simultaneously on more than one actor in their collaborations related to acquiring external knowledge, mainly on their customers and suppliers, most frequently from at least two different spatial levels. The knowledge gathered from competitors is more relevant in case of non-innovative firms, 
while higher educational institutions are evidently important only in case of innovative firms. Innovative firms rely mostly on their local customers and national, as well as international suppliers, while non-innovative companies, besides their local and national customers, build on knowledge acquired from local competitors. Consequently, local tacit knowledge, although from different actors, is important for both firm types, while knowledge acquired from the international level and from higher educational institutions is only relevant for innovative firms.

\section{Conclusions}

Our results strengthen the argument of Asheim et al. (2011), Tödtling and Grillitsch (2015), Zukauskaite and Moodysson (2013) that there is no industry which can be defined by only one knowledge base. The composition of workforce indicates that the printing industrial firms of Kecskemét are dominated by synthetic knowledge base, but activities characterised by symbolic knowledge base are also present. In the case of innovative firms, the composition of workforce is more evenly divided between the different activities (and knowledge bases). This finding is well in line with other studies which argue that innovative firms rely on the combination of at least two knowledge bases (Tödtling and Grillitsch, 2015; Zukauskaite and Moodysson, 2013).

Examining the main sources of knowledge acquisition, the pattern identified in the industry is slightly different from prior assumptions. Based on the results of Martin and Moodysson (2013) secondary sources are not of major importance for firms in synthetic knowledge-based industries whereas our results show otherwise. The necessity of indirect knowledge sources can be explained by the facts that, first, the firms satisfy unique consumer demands, which are created by learning about different solutions and combining them in a new way; secondly, it is practical to exploit the most possible knowledge sources in a peripheral region; thirdly, the willingness of firms to collaborate is moderate, collecting and 'picking up' ideas can be realised mostly through indirect sources; and finally characteristics of symbolic knowledge base, where less formalised knowledge sources such as specialised magazines, fairs and exhibitions are important, is also present in the industry. The latter is supported by more in the literature (Gülcan et al., 2011; Martin and Moodysson, 2013).

Furthermore, although the examination of the total sample may imply that scientific secondary sources are quite insignificant within the industry, the categorisation of innovative and non-innovative firms clearly shows that the firms performing innovation activities rely on these sources as well. This is surprising compared to Martin and Moodysson's (2013) results, because they proved that scientific sources considered being of very little importance in a synthetic knowledge-based industry. However, our findings indicate that the creation of innovations requires scientific findings alongside practical experience.

The main partners related to knowledge acquisition and transfer activities of firms were examined within the dimensions of mobility and collaboration. The firms attribute surprisingly low importance to skilled workforce recruitment in their knowledge sourcing activities. Despite the fact that specific technical knowledge is also required in the industry, the importance of higher educational institutions and vocational training schools is extremely low. The innovative firms rely on them, although to a smaller extent. However, the high importance of actors within the industry confirms our theoretical 
assumptions as in synthetic knowledge-based industries, which are characterised by experimenting, testing and learning-by-doing, the role of workforce with practical experience is more prominent. The firms thus rely on higher educational and vocational training institutions to a lesser degree because they are more likely to prepare their own workforce.

Studying collaborations reveals that this is the most important means of knowledge acquisition within the industry. The companies collaborate with several actors at the same time in the process of gathering new knowledge. The results draw the attention primarily to the higher importance of customers and suppliers. Customers are more or less of similar importance for innovative and non-innovative firms. However, while the former group considers suppliers even more important, the latter attributes lower importance to suppliers and higher to competitors. The cooperation with higher educational institutions is important almost exclusively to innovative firms, which reinforces our former arguments regarding the necessity of scientific findings. Furthermore, innovative firms frequently complement the knowledge originating from higher educational institutions with knowledge from other actors. The combination of these sources might be highly relevant if the innovation is specific, problem-oriented and based on applied research.

Finally, we also examined the spatial levels of knowledge acquisition within the dimensions of mobility and collaboration. In the recruitment of new skilled workforce, the local level proved to be the most important for innovative and, in particular, non-innovative firms. Moreover, non-innovative firms recruit new workforce members almost exclusively from here. Innovative firms, alongside local actors, rely on national and international actors, but it only complements the recruitment from the local level in each case. All this indicates the higher importance of tacit knowledge within the industry as firms seem to search for employees who are aware of the local characteristics. The prevalence of the local level is not so evident in the direct collaboration of actors. In the case of non-innovative firms, locally realised knowledge acquisition proved to be the most important, but in the case of direct collaborations, it is complemented by knowledge from national and international actors. On the other hand, innovative firms simultaneously acquire knowledge from all three spatial levels which reinforces the argument of Tödtling and Grillitsch (2015) who found that knowledge acquired from more than one spatial level leads to higher innovation performance of firms. These observations point out that the local level is of primary importance in the process of acquiring new knowledge in a traditional industry with a synthetic knowledge base because of context-specific knowledge. Nevertheless, the innovation activities of the firms also require knowledge from outside the region, which may originate from the innovation activity or the peripheral character of the region, i.e., from the insufficient extent and quality of locally accessible knowledge.

Our most important contribution to the literature is twofold. First, our observations point out that the role of local embeddedness in knowledge sourcing has not only moderate, but high importance because of context-specific knowledge-based activities. However, admittedly, there is a need for external knowledge sources as well. Second, the pattern of knowledge sourcing activity is not only the matter of industrial knowledge base, but among others, it depends on the nature of the demand, the peripheral status of the regional environment and the willingness of cooperation. The latter alone depends on many factors like historical background, cultural norms or trust. 


\section{Summary}

In our paper, we attempted to map the learning and knowledge sourcing processes of a traditional industry concentrated in a peripheral region, for which our analysis focused on the printing industry of Kecskemét in Hungary. Our study was based on the theory of differentiated knowledge bases, according to which we regarded the printing industry as an industry characterised dominantly by a synthetic knowledge base. We considered the printing industry in Kecskemét as a suitable case owing to the relatively high geographical concentration of the industry, its remarkable history and the similar social and historical background of the firms. We aimed to analyse knowledge sourcing related to innovation in light of secondary knowledge sources, partnerships and spatiality.

Our results indicate that even if we consider a traditional industry in a peripheral region, half of the firms are capable of innovation; in addition, innovative and non-innovative firms differ in terms of learning and knowledge sourcing processes. Innovative firms rely simultaneously on several indirect and direct sources in their knowledge acquisition and transfer activities. The analysis of the spatial levels also indicates that although the local level has a prominent role in terms of knowledge sourcing, innovation also requires substantial knowledge from outside the region, which can be accessed from both national and international actors. Innovative firms build on the widest possible range of available knowledge sources, within and outside the region, which can be traced back to a higher demand for knowledge, as well as the peripheral nature of the region and the lack of locally accessible new knowledge.

On the other hand, non-innovative firms rely primarily on the local level and their knowledge acquisition activities are characterised by the use of incomplex, simple knowledge sources (customers, suppliers, exhibitions, professional magazines). Overall, our assumptions seem to be confirmed regarding the printing industry of Kecskemét as a traditional industry with a dominantly synthetic knowledge base. The discrepancies we found are explained by the prominent presence of the SMEs specialised in the manufacture of unique products, the innovation activity of the firms and the peripheral character of the region.

The research also revealed that the printing industry as a traditional industry is not considered as a leading industry in the peripheral region of Kecskemét. The latest strategic objectives focus on the promotion of R\&D-oriented activities, and not that of traditional industries. Based on the findings of the present research, however, the companies of traditional industries can also have considerable innovation potential, and owing to their extensive networks of partnerships and their role in employment, they are crucial for the local economy. In our view, the exploitation of the economic potential of the studied printing industry located in the less developed region requires the promotion of networking between the firms and the encouragement of investments serving the satisfaction of individual, and even international, consumer demands and sales activities. Although some firms interact with international partners, the innovation potential could be further increased by expanding the number of global pipelines.

In policy-making, more emphasis should be put on the exploitation of possibilities in the innovation activities of traditional industries in less developed regions. Although peripheral regions lag behind the advanced, even metropolitan regional innovation systems, the sources of their growth are different and they have the chance to exploit possibilities which stem from the specialisation in traditional industrial activities, locally embedded companies being aware of local characteristics and having an identical 
historical and cultural background. Enhancing cluster initiatives in the city region, improving the cooperation between firms and educational institutions and developing non-R\&D-based innovation projects could be advantageous policy instruments.

Although our research has been built on a well elaborated theory and a tested method some limitations should be mentioned. First, the research has been taken place in a local area so our sample is too small to develop general statements for traditional industries. Second, our case study concerns only a single industry in one local economy. Conducting the research in another traditional industry or local area could provide a deeper insight to the topic. Finally a dominant knowledge base could be identified in an industry but it can change in line with the lifecycle of the industry.

To explore more peculiarities of the industry and its development path, further research is needed. Due to the fact that dominant knowledge base may differ over the time, empirical research should be repeated for comparison. In-depth interviews with the entrepreneurs may reveal how the industry can make improvements along the three analysed dimensions of knowledge sourcing. Questioning policy-makers can also explain why the industry is neglected in planning.

\section{Acknowledgements}

The authors are grateful to Sándor Juhász and Katalin Kiss for their help in data collection. This research was supported by the Project No. EFOP-3.6.2-16-2017-00007, titled "Aspects on the development of intelligent, sustainable and inclusive society: social, technological, innovation networks in employment and digital economy". The project has been supported by the European Union, co-financed by the European Social Fund and the budget of Hungary.

\section{References}

Asheim, B. and Gertler, M.C. (2005) 'The geography of innovation: regional innovation systems', in Fagerberg, J. et al. (Eds.): The Oxford Handbook of Innovation, pp.291-317, Oxford University Press, Oxford; New York.

Asheim, B., Boschma, R. and Cooke, P. (2011) 'Constructing regional advantage: platform policies based on related variety and differentiated knowledge bases', Regional Studies, Vol. 45, No. 7, pp.893-904, DOI: 10.1080/00343404.2010.543126.

Asheim, B., Coenen, L. and Vang, J. (2007) 'Face-to-face, buzz, and knowledge bases: sociospatial implications for learning, innovation, and innovation policy', Environment and Planning C, Vol. 25, No. 5, pp.655-670, DOI: 10.1068/c0648.

Bathelt, H., Malmberg, A. and Maskell, P. (2004) 'Clusters and knowledge: local buzz, global pipelines and the process of knowledge creation', Progress in Human Geography, Vol. 28, No. 1, pp.31-56, DOI: 10.1191/0309132504ph469oa.

Boschma, R.A. (2005) 'Proximity and innovation: a critical assessment', Regional Studies, Vol. 39, No. 1, pp.61-74, DOI: 10.1080/0034340052000320887.

Camagni, R.P. (1995) 'The concept of innovative milieu and its relevance for public policies in European lagging regions', Regional Science, Vol. 74, No. 4, pp.317-340, DOI: 10.1111/ j.1435-5597.1995.tb00644.x.

Chaminade, C. (2011) 'Are knowledge bases enough? A comparative study of the geography of knowledge sources in China (Great Beijing) and India (Pune)', European Planning Studies, Vol. 19, No. 7, pp.1357-1373, DOI: 10.1080/09654313.2011.573171. 
Chesbrough, H. (2003) 'The logic of open innovation: managing intellectual property', California Management Review, Vol. 45, No. 3, pp.33-58, DOI: 10.2307/41166175.

Chesbrough, H. and Crowther, A.K. (2006) 'Beyond high tech: early adopters of open innovation in other industries', $R \& D$ Management, Vol. 36, No. 3, pp.229-236, DOI: 10.1111/ j.1467-9310.2006.00428.x.

Cohen, W.M. and Levinthal, D.A. (1990) 'Absorptive capacity: a new perspective on learning and innovation', Administrative Science Quarterly, Vol. 35, No. 1, pp.128-152, DOI: 10.2307/ 2393553.

Cooke, P. and Morgan, K. (1993) 'The network paradigm: new departures in corporate and regional development', Environment and Planning D: Society and Space, Vol. 11, No. 5, pp.543-564, DOI: $10.1068 / \mathrm{d} 110543$.

Csizmadia, Z. and Grosz, A. (2011) Innovation and Cooperation Networks in Hungary, Centre for Regional Studies Hungarian Academy of Sciences, Discussion papers, Vol. 85, Pécs.

Dosi, G. (1988) 'Sources, procedures, and microeconomic effects of innovation', Journal of Economic Literature, Vol. 26, No. 3, pp.1120-1171.

Florida, R. (1995) 'Toward the learning region', Futures, Vol. 27, No. 5, pp.527-536.

Grant, R.M. (1996) 'Toward a knowledge-based theory of the firm', Strategic Management Journal, Vol. 17, No. 2, pp.109-122, DOI: 10.1002/smj.4250171110.

Gülcan, Y., Akgüngör, S. and Kuştepeli, Y. (2011) 'Knowledge generation and innovativeness in Turkish textile industry: comparison of Istanbul and Denizli', European Planning Studies, Vol. 19, No. 7, pp.1229-1243, DOI: 10.1080/09654313.2011.573134.

Jensen, M.B., Johnson, B., Lorenz, E. and Lundvall, B-A. (2007) 'Forms of knowledge and modes of innovation', Research Policy, Vol. 36, No. 5, pp.680-693, DOI: 10.1016/ j.respol.2007.01.006.

Juhász, S. and Lengyel, B. (2016) 'Tie creation versus tie persistence in cluster knowledge networks', Evolutionary Economic Geography, No. 1613, Utrecht University: Section of Economic Geography.

Kaufmann, A. and Tödtling, F. (2000) 'Systems of innovation in traditional industrial regions: the case of Syria in a comparative perspective', Regional Studies, Vol. 34, No. 1, pp.29-40, DOI: $10.1080 / 00343400050005862$

Krafft, J., Quatraro, F. and Saviotti, P.P. (2014) 'The dynamics of knowledge-intensive sectors' knowledge base: evidence from biotechnology and telecommunications', Industry and Innovation, Vol. 21, No. 3, pp.215-242, DOI: 10.1080/13662716.2014.919762.

Lagendijk, A. and Lorentzen, A. (2007) 'Proximity, knowledge and innovation in peripheral regions: on the intersection between geographical and organizational proximity', European Planning Studies, Vol. 15, No. 4, pp.457-466, DOI: 10.1080=09654310601133260.

Lengyel, B. (2012) Tudásalapú regionális fejlödés (Knowledge-based Regional Development), L'Harmattan Kiadó, Budapest.

Lengyel, B. and Leydesdorff, L. (2011) 'Regional innovation systems in Hungary: the failing synergy at the national level', Regional Studies, Vol. 45, No. 5, pp.677-693, DOI: 10.1080/ 00343401003614274.

Lengyel, I. and Rechnitzer, J. (2013) 'Drivers of regional competitiveness in the central European countries', Transition Studies Review, Vol. 20, No. 3, pp.421-435, DOI: 10.1007/ s11300-013-0294-2.

Levitt, B. and March, J.G. (1988) 'Organizational learning', Annual Review of Sociology, Vol. 14, No. 1, pp.319-340, DOI: 10.1146/annurev.so.14.080188.001535.

Liu, J., Chaminade, C. and Asheim, B. (2013) 'The geography and structure of global innovation networks: a knowledge base perspective', European Planning Studies, Vol. 21, No. 9, pp.1456-1473, DOI: 10.1080/09654313.2012.755842.

Lundvall, B-A. (Ed.) (1992) National System of Innovation: Towards a Theory of Innovation and Interactive Learning, Pinter Publisher, London. 
Malmberg, A. and Maskell, P. (2006) 'Localized learning revisited', Growth and Change, Vol. 37, No. 1, pp.1-18, DOI: 10.1111/j.1468-2257.2006.00302.x.

Martin, R. and Moodysson, J. (2011) 'Innovation in symbolic industries: the geography and organization of knowledge sourcing', European Planning Studies, Vol. 19, No. 7, pp.1183-1203, DOI: 10.1080/09654313.2011.573131.

Martin, R. and Moodysson, J. (2013) 'Comparing knowledge bases: on the geography and organization of knowledge sourcing in the regional innovation system of Scania, Sweden', European Urban and Regional Studies, Vol. 20, No. 2, pp.170-187, DOI: 10.1177/ 0969776411427326.

Plum, O. and Hassink, R. (2011) 'Comparing knowledge networking in different knowledge bases in Germany', Regional Science, Vol. 90, No. 2, pp.355-371, DOI: 10.1111/ j.1435-5957.2011.00362.x.

Rosenfeld, S.A. (2002) Creating Smart Systems: A Guide to Cluster Strategies in Less Favoured Regions, European Union and Regional Innovation Strategies, Regional Technology Strategies, Carrboro, North Carolina.

Simon, H.A. (1991) 'Bounded rationality and organizational learning', Organisation Science, Vol. 2, No. 1, pp.125-134, DOI: 10.1287/orsc.2.1.125.

Spithoven, A., Clarysse, B. and Knockaert, M. (2011) 'Building absorptive capacity to organise inbound open innovation in traditional industries', Technovation, Vol. 31, No. 1, pp.10-21, DOI: 10.1016/j.technovation.2009.08.004.

Szakálné, K.I. and Vas, Z. (2013) 'Spatial distribution of knowledge-intensive industries in Hungary', Transition Studies Review, Vol. 19, No. 4, pp.431-444, DOI: 10.1007/ s11300-013-0261-y.

Tödtling, F. and Grillitsch, M. (2015) 'Does combinatorial knowledge lead to a better innovation performance of firms?', European Planning Studies, Vol. 23, No. 9, pp.1741-1758, DOI: $10.1080 / 09654313.2015 .1056773$.

Tödtling, F. and Trippl, M. (2005) 'One size fits all?: Towards a differentiated regional innovation policy approach', Research Policy, Vol. 34, No. 8, pp.1203-1209, DOI: 10.1016/ j.respol.2005.01.018.

Tödtling, F., Lehner, P. and Trippl, M. (2006) 'Innovation in knowledge intensive industries: the nature and geography of knowledge links', European Planning Studies, Vol. 14, No. 8, pp.1035-1058, DOI: 10.1080/09654310600852365.

Tödtling, F., Lengauer, L. and Höglinger, C. (2011) 'Knowledge sourcing and innovation on 'thick' and 'thin' regional innovation systems - comparing ICT firms in two Austrian regions', European Planning Studies, Vol. 19, No. 7, pp.1245-1276, DOI: 10.1080/ 09654313.2011 .573135 .

Trippl, M. (2011) 'Regional innovation systems and knowledge-sourcing activities in traditional industries: evidence from the Vienna food sector', Environment and Planning A, Vol. 43, No. 7, pp.1599-1616, DOI: 10.1068/a4416.

Vega-Jurado, J., Gutiérrez-Gracia, A. and Fernández-de-Lucio, I. (2009) 'Does external knowledge sourcing matter for innovation? Evidence from the Spanish manufacturing industry', Industrial and Corporate Change, Vol. 18, No. 4, pp.637-670.

Zukauskaite, E. and Moodysson, J. (2013) Multiple Paths of Development: Knowledge Bases and Institutional Characteristics of the Swedish Food Sector, Lund University, CIRCLE-Center for Innovation, Research and Competences in the Learning Economy, No. 2013/46. 